WSRC-TR-2002-00054

Revision 0

Key Words: Criticality HLW

Solubility

Dilution

Hydroxide

\title{
Potential for the Precipitation of Uranium and Plutonium Solids upon Addition of Nitric Acid to Waste Solutions in a Caustic-Side Solvent Extraction Process
}

D. T. Hobbs

Publication Date: May 10, 2002 
This document was prepared in conjunction with work accomplished under Contract No. DE-AC09-96SR18500 with the U. S. Department of Energy.

\section{DISCLAIMER}

This report was prepared as an account of work sponsored by an agency of the United States Government. Neither the United States Government nor any agency thereof, nor any of their employees, makes any warranty, express or implied, or assumes any legal liability or responsibility for the accuracy, completeness, or usefulness of any information, apparatus, product or process disclosed, or represents that its use would not infringe privately owned rights. Reference herein to any specific commercial product, process or service by trade name, trademark, manufacturer, or otherwise does not necessarily constitute or imply its endorsement, recommendation, or favoring by the United States Government or any agency thereof. The views and opinions of authors expressed herein do not necessarily state or reflect those of the United States Government or any agency thereof.

This report has been reproduced directly from the best available copy.

Available for sale to the public, in paper, from: U.S. Department of Commerce, National Technical Information Service, 5285 Port Royal Road, Springfield, VA 22161, phone: (800) 553-6847, fax: (703) 605-6900

email: orders@ntis.fedworld.gov

online ordering: http://www.ntis.gov/help/index.asp

Available electronically at http://www.osti.gov/bridge

Available for a processing fee to U.S. Department of Energy and its contractors, in paper, from: U.S. Department of Energy, Office of Scientific and Technical Information, P.O. Box 62, Oak Ridge, TN 37831-0062,

phone: (865)576-8401,

fax: (865)576-5728

email: $\underline{\text { reports@ adonis.osti.gov }}$ 


\section{Approvals:}

D.T. $5 / 6 / 02$

D. T. Hobbs, WPTS Researcher Date

Darrel O. Walker $5 / 7 / 02$

D. D. Walker, WPTS Design Check Date

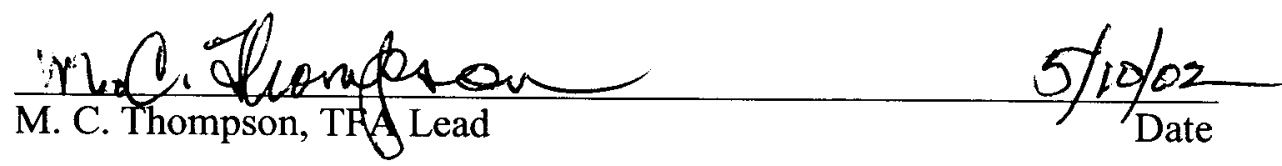

$\frac{17 \log 6}{\text { T. Carter, Director of Engineering, SPP }}$
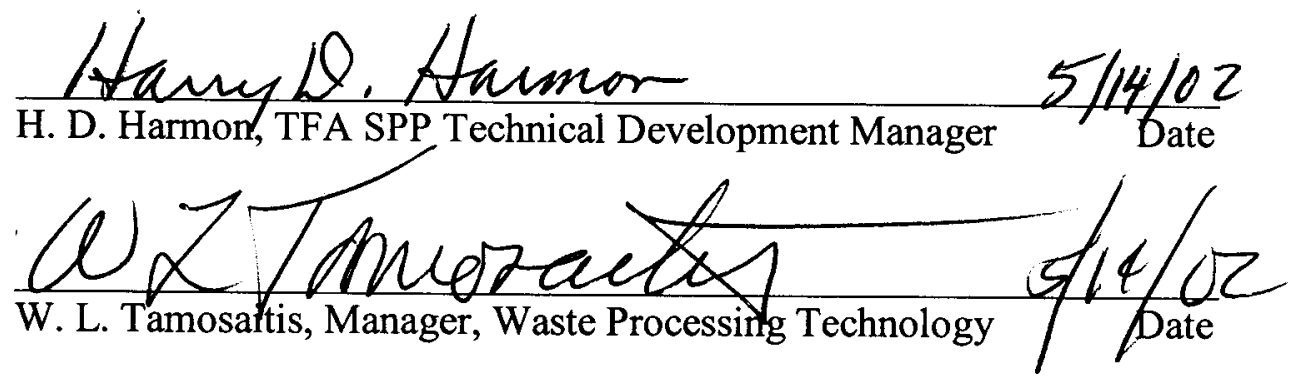
WSRC-TR-2002-00054

\section{Summary}

Models predict that uranium and plutonium concentrations can exceed the predicted solubilities when scrub acid solution ( $0.2 \mathrm{M}$ nitric acid) mixes with alkaline waste solutions in the caustic-side solvent extraction (CSSX) stages of the planned Salt Processing Pilot Plant Facility and the full-scale Salt Waste Processing Facility. However, in all cases, including the simultaneous precipitation of both uranium and plutonium, the quantities of precipitated uranium and plutonium solids are well below the fissionable mass limits for ${ }^{235} \mathrm{U}$ and ${ }^{239} \mathrm{Pu}$.

Under normal operations at nominal contact volumes and times, the prediction models indicate that uranium would not precipitate in the CSSX stage, but could precipitate after mixing with large volumes of scrub acid solution and extended storage in the decontaminated waste solution storage tanks. We estimate that the maximum quantity of uranium precipitated in the pilot plant facility (diluted waste volume of 1680 gallons) at 5.0 grams and in the full-scale facility at 296 grams (diluted waste volume of 100,000 gallons). These quantities are well below the ${ }^{235} \mathrm{U}$ mass limit of 700 grams.

Under normal operations at nominal contact volumes, plutonium precipitation could occur during the CSSX stage if the feed waste solution enters saturated in plutonium. However, we estimate that the maximum quantity of plutonium precipitated in the pilot plant facility at 1.1 grams and in the full-scale facility at 150 grams at the fully saturated condition. These quantities are well below the fissionable mass limit for ${ }^{239} \mathrm{Pu}$ of 450 grams. In actuality, the quantities of plutonium will be much lower than this value as greater than $90 \%$ of the plutonium in the feed waste solution will be removed during the $\mathrm{Sr} /$ Alpha separation process prior to processing in the CSSX stage.

\section{Introduction}

The Department of Energy identified CSSX as the preferred process to replace the InTank Precipitation process to decontaminate liquid radioactive waste at the Savannah River Site (SRS). ${ }^{1}$ The CSSX process uses a calixarene-based solvent system to extract cesium from alkaline waste. ${ }^{2}$ Scrubbing and stripping of cesium from the solvent provides a homogeneous, dilute acid aqueous stream containing the cesium. Previous testing with simulated and radioactive waste solutions demonstrated the feasibility of the process. $^{3}$

One of the next phases of development of the CSSX process involves building a demonstration facility. This facility will resemble a previously proposed pilot plant ${ }^{4}$ with the capability of processing sufficient real waste volume that contains more than a critical mass of ${ }^{235} \mathrm{U}$ and ${ }^{239} \mathrm{Pu}$. The nuclear criticality safety evaluation ${ }^{5}$ (NCSE) of the pilot facility identified two safety issues. The first relates to a potential change in uranium and plutonium solubility in the extraction bank because of the addition of the scrub acid. Addition of the scrub acid, which may have a nitric acid concentration as high as $0.2 \mathrm{M}$, will decrease the hydroxide concentration or $\mathrm{pH}$ of the HLW solution. The decrease in the $\mathrm{pH}$ will reduce the solubilities of uranium and plutonium. If the resulting solutions contain uranium and plutonium above their respective solubilities, precipitation of pure uranium and plutonium solids can occur. 
WSRC-TR-2002-00054

A number of prior studies investigated the solubility of uranium and plutonium in similar waste. ${ }^{6}$ Based on the data from those studies, the author led development of predictive solubility models. This report used these models to calculate uranium and plutonium solubility versus solution compositions before and after mixing waste solution with scrub acid. These calculations provide estimated quantities of precipitated uranium and plutonium. This work is a deliverable identified in "Task Technical and Quality Assurance Plan Supporting CSSX Pilot Plant Criticality Issues."7 This plan describes tests and calculations to assess the issues raised by Ross ${ }^{5}$ and fulfills the requested information from Campbell. ${ }^{8}$

Subsequent to the start of this work, the Department of Energy reached a decision to bypass construction of a pilot plant and instead construct a demonstration facility. The demonstration facility will begin treatment of actual waste while simultaneously performing the pilot plant function. The data obtained in this work supports criticality evaluations for the demonstration facility.

\subsection{Calculation Methodology}

\subsection{Solubility Models}

Prediction of uranium and plutonium concentrations used equations $1-3$. These equations calculate uranium and plutonium concentrations as a function of temperature and the major anionic solution components; hydroxide, nitrate, nitrite, aluminate, carbonate and sulfate. For uranium, predictive equations derive from concentration data at two different times upon assembly of the test solutions, 4 days and 129 days. The 4day model represents a non-equilibrium condition including the possibility of solutions unsaturated or supersaturated in uranium. The 129-day model represents equilibrium or near-equilibrium conditions.

$$
\begin{aligned}
\text { Equation 1: 4-Day Prediction Equation for Uranium Concentration } & 9 \\
\log [\mathrm{U}]= & 0.805-0.000864 * \mathrm{~T}-1.17 * \log [\mathrm{OH}]-0.272 * \log \left[\mathrm{AlO}_{2}\right]-0.250 * \log \left[\mathrm{CO}_{3}\right]+ \\
& 0.200 * \log \left[\mathrm{NO}_{3}\right]+0.0563 * \log \left[\mathrm{NO}_{2}\right]+0.189 * \log \left[\mathrm{SO}_{4}\right]+ \\
& 0.108 * \log \left[\mathrm{AlO}_{2}\right] * \log [\mathrm{OH}]-0.262 * \log \left[\mathrm{CO}_{3}\right] * \log [\mathrm{OH}]+ \\
& 0.130 * \log \left[\mathrm{NO}_{3}\right] * \log [\mathrm{OH}]+0.131 * \log \left[\mathrm{NO}_{2}\right] * \log [\mathrm{OH}]- \\
& 0.00186 * \log \left[\mathrm{SO}_{4}\right] * \log [\mathrm{OH}]+0.00586 * \mathrm{~T}^{*} \log [\mathrm{OH}]+ \\
& 0.0757 * \log \left[\mathrm{NO}_{2}\right] * \log \left[\mathrm{NO}_{3}\right]+0.0325 * \log \left[\mathrm{NO}_{3}\right] * \log \left[\mathrm{NO}_{2}\right] * \log [\mathrm{OH}]- \\
& 0.349 * \log [\mathrm{OH}] * \log [\mathrm{OH}]
\end{aligned}
$$

Equation 2: 129-Day Prediction Equation for Uranium Concentration ${ }^{9}$

$$
\begin{aligned}
\hline \log [\mathrm{U}]= & 1.415-0.009 * \mathrm{~T}+0.202 * \log [\mathrm{OH}]-0.022 * \log \left[\mathrm{AlO}_{2}\right]+0.619 * \log \left[\mathrm{CO}_{3}\right]- \\
& 0.360 * \log \left[\mathrm{NO}_{3}\right]-0.321 * \log \left[\mathrm{NO}_{2}\right]-0.125 * \log \left[\mathrm{SO}_{4}\right]+0.319 * \log \left[\mathrm{AlO} \mathrm{O}_{2}\right] * \log [\mathrm{OH}] \\
& -0.266 * \log \left[\mathrm{CO}_{3}\right] * \log [\mathrm{OH}]-0.129 * \log \left[\mathrm{NO}_{3}\right] * \log [\mathrm{OH}]- \\
& 0.117 * \log \left[\mathrm{NO}_{2}\right] * \log [\mathrm{OH}]-0.108 * \operatorname{logSO} 4 * \log [\mathrm{OH}]+0.007 * \mathrm{~T} * \log [\mathrm{OH}]- \\
& 0.123 * \log \left[\mathrm{NO}_{2}\right] * \log \left[\mathrm{NO}_{3}\right]-0.088 * \log \left[\mathrm{NO}_{3}\right] * \log \left[\mathrm{NO}_{2}\right] * \log [\mathrm{OH}]+ \\
& 0.121 * \log [\mathrm{OH}] * \log [\mathrm{OH}]
\end{aligned}
$$


WSRC-TR-2002-00054

Equation 3: Prediction Equation for Plutonium ${ }^{10}$

$\log [\mathrm{Pu}]=-0.6493+1.27 * \log [\mathrm{OH}]+0.505 * \log [\mathrm{OH}] * \log [\mathrm{OH}]$

where, $[\mathrm{U}]=$ concentration of uranium in $\mathrm{mg} / \mathrm{L}$,

$[\mathrm{Pu}]=$ concentration of plutonium in mole/L,

$\mathrm{T}=$ Temperature in ${ }^{\circ} \mathrm{C}$,

$[\mathrm{OH}]=$ concentration of hydroxide in mole $/ \mathrm{L}$,

$\left[\mathrm{NO}_{3}\right]=$ concentration of nitrate in mole/L,

$\left[\mathrm{NO}_{2}\right]=$ concentration of nitrite in mole/L,

$\left[\mathrm{AlO}_{2}\right]=$ concentration of aluminate in mole $/ \mathrm{L}$,

$\left[\mathrm{CO}_{3}\right]=$ concentration of carbonate in mole/ $\mathrm{L}$, and

$\left[\mathrm{SO}_{4}\right]=$ concentration of sulfate in mole/L.

Table I provides the range of temperatures and compositions from which we developed the uranium prediction equation. ${ }^{9}$ The range of hydroxide and nitrate components evaluated with the four cases spans that expected for waste treated in the SWPF.

Temperatures in the solubility testing spanned the range from 27 to $85^{\circ} \mathrm{C}$. Results indicated that temperature exhibited a minor affect on uranium solubility. In both models, uranium solubility decreased with increasing temperature. An inverse temperature dependence on solubility is rare, but not unknown, for inorganic compounds.

Table I. Range of Solution Composition and Temperatures in Previous Uranium Solubility Testing

\begin{tabular}{|c|c|c|}
\hline$\frac{\text { Parameter }}{\text { Temperature }}$ & $\frac{\text { Minimum Value }}{27}$ & $\frac{\text { Maximum Value }}{85}$ \\
\hline Hydroxide & $1.27 \mathrm{E}-04$ & 17.1 \\
\hline Nitrate & $5.81 \mathrm{E}-04$ & 7.18 \\
\hline Nitrite & $2.17 \mathrm{E}-04$ & 4.50 \\
\hline Aluminate & $2.75 \mathrm{E}-04$ & 1.95 \\
\hline Carbonate & 4.13E-05 & 0.993 \\
\hline Sulfate & $1.04 \mathrm{E}-04$ & 0.435 \\
\hline
\end{tabular}

Extraction and stripping parameters exhibit marked temperature dependencies during the CSSX stage and, consequently, temperature will be controlled during the CSSX stage.

The expected temperatures range from 15 to $40{ }^{\circ} \mathrm{C}$. The lower temperature is outside that investigated in the uranium solubility testing. To bound the effect of temperature on the predicted quantities of precipitated uranium, we performed calculations over the range from 27 to $85^{\circ} \mathrm{C}$ and used the temperature case that produced the maximum precipitation. The results indicated an inverted $\mathrm{U}$-shaped curve producing a predicted maximum precipitation between 35 and $45^{\circ} \mathrm{C}$ for the "High Hydroxide", "Average" and 
WSRC-TR-2002-00054

"High Nitrate" cases and $65^{\circ} \mathrm{C}$ for the "Average with High Carbonate" case (see Figure $1)$.

We used the maximum predicted concentration of precipitated solids to calculate the maximum quantity of precipitated solids at various volumes of diluted waste (see section 4.3). Note that using the maximum concentration regardless of whether the temperature at which the maximum occurs provides a conservative estimate of precipitated solids for those cases where the maximum occurs higher than the maximum operating temperature of $40{ }^{\circ} \mathrm{C}$ in the CSSX process.

\section{Figure 1. Predicted Maximum Quantity of Precipitated Uranium Solids upon Dilution of Waste Solution with 0.2 M Nitric Acid}

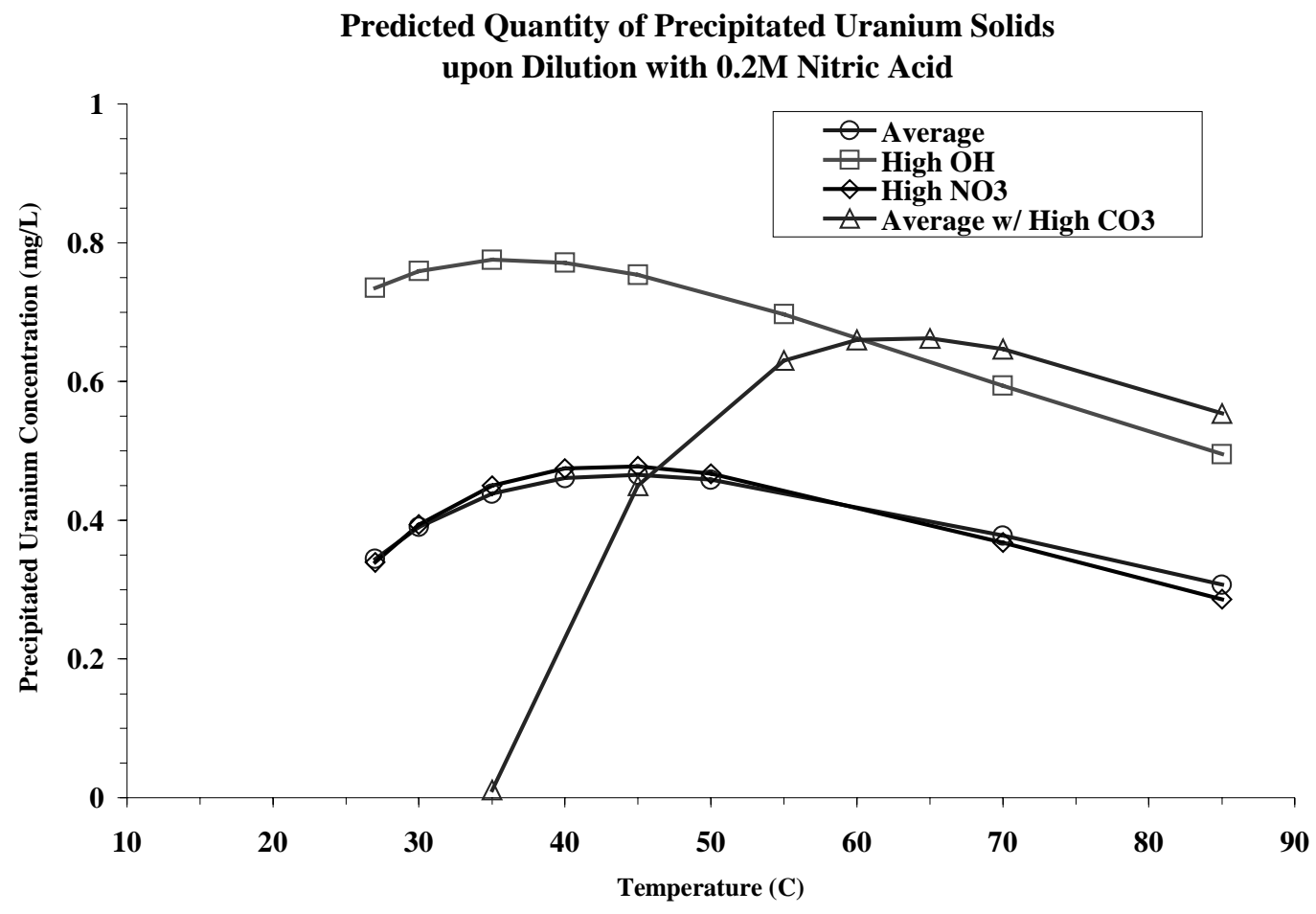

Note that the 4-day prediction equation (equation 1) may not provide conservative estimates due to the experimental method used in preparing the solutions for testing. For the solubility tests, researchers added a quantity of a uranyl nitrate solution to the appropriate alkaline salt solution. Addition of a large excess of uranyl nitrate ensured that the quantity of uranium added to each test solution exceeded the uranium solubility. Most of the uranium immediately formed a solid precipitate upon contact with the alkaline solution. With time the precipitated uranium solids will dissolve if the solution is unsaturated in uranium until the solution reaches saturation. Thus, the 4-day data or some part thereof may represent solutions unsaturated in uranium. Conversely, since an excess of uranium was added to the solution, the 4-day data or some part thereof may reflect solutions supersaturated in uranium or that contain uranium solids small enough to pass through the filter pores. In this case, the apparent uranium concentration exceeds the 
solubility. With time the system will move to either precipitate or crystallize the uranium into larger particles until the system reaches equilibrium. Examination of the concentration time profiles indicates that both unsaturated and supersaturated conditions existed during the early stages of the solubility tests. Thus, the 4-day prediction equation may not necessarily provide conservative estimates since the equation derives in part from tests supersaturated in uranium.

Tests in 2-cm solvent extraction equipment indicate residence times of approximately 0.5 minutes per contactor in the extraction stage for the CSSX process. ${ }^{11,12}$ Similar residence times are expected in the larger pilot-scale and full-scale equipment. As a consequence of the short residence times non-equilibrium conditions will most likely prevail upon mixing the scrub acid solution with the alkaline waste in the contactors. Treated waste solutions feed forward to the decontaminated waste solution storage tank for feed to Saltstone. The residence time of waste solution contacted with scrub acid solution stored in this tank is longer than that in the contactors and, with extended shutdown of the operations, conditions within this tank could approach equilibrium. For completeness we chose to evaluate predicted uranium concentrations using both the 4-day (nonequilibrium) and 129-day (equilibrium) prediction equations.

\subsection{Calculation Bases}

Calculations examined four solution compositions referred to as "High Hydroxide"13, "Average"13 "High Nitrate"13 and "Average with High Carbonate". Table II provides the compositions for these four solutions. For the case "Average with High Carbonate", we increased the carbonate concentration to $0.50 \mathrm{M}$. Carbonate is known to form stable complexes with actinides - particularly uranium - and, therefore, could impact the solubility of uranium in the waste solutions. The calculations assume all other components for this case at the concentrations for the "Average" composition. All calculations assume a temperature that produces the highest quantity of precipitated solids for the respective solution compositions.

Calculations assume addition of increments of scrub acid at the volume ratio planned for CSSX operations, 1 volume of scrub acid to 15 volumes of waste solution. The calculations fix the concentration of nitric acid in the scrub acid at the maximum value of $0.2 \mathrm{M}$. The nitric concentration planned for normal operations is 0.05 molar. Using the maximum concentration value provides the greatest degree of neutralization with the smallest dilution factor. We assumed that the volume of the solution produced by mixing the waste solution and the scrub acid solution simply equaled the sum of the waste and scrub acid volumes.

To calculate the quantity of precipitated solids, we set the initial concentration at one of four conditions: (1) saturated (i.e., at the calculated solubility limit), (2) 75\% of the saturated value, (3) $50 \%$ of the saturated value and (4) $25 \%$ of the saturated value and multiplied this condition by the appropriate dilution factor for each incremental addition of scrub acid. This range of uranium and plutonium saturation spans the range of concentrations that will process through the CSSX process. Normally, uranium and plutonium are removed by the strontium/alpha process that immediately precedes the 
WSRC-TR-2002-00054

CSSX process. Thus, uranium and plutonium concentrations will enter the CSSX below their respective solubilities. Only in an off-normal event in which waste solution passes through to the CSSX stage without strontium/alpha removal will the uranium and plutonium concentrations enter at their solubility limits.

There is also a possibility that supersaturated solutions could be produced upon dissolution of saltcake, which then could be sent to the CSSX contactors without strontium/alpha removal. Dissolution of saltcake containing uranium salts has not been extensively studied with regards to uranium dissolution. Thus, there is insufficient experimental data to estimate the degree of supersaturation that could be achieved. We judge the likelihood to produce supersaturated solutions during saltcake dissolution to be very low as the planned dissolution conditions do not promote formation of supersaturated solutions (e.g., no evaporation at high temperature and no rapid change in solution $\mathrm{pH})$.

We then calculated the difference between the predicted solubility and that for one of the four conditions at each incremental scrub acid addition step. A positive value indicated that the solubility of the uranium or plutonium exceeds the incremental condition and that no precipitation would occur. A negative value indicates that the incremental condition concentration exceeds the predicted solubility and that precipitation of solids could occur.

\section{Table II. Solution Compositions}

\begin{tabular}{|c|c|c|c|c|}
\hline \multicolumn{5}{|c|}{ Concentration (M) } \\
\hline Component & High $\mathrm{OH}^{-}$ & Average & Average w/ High $\mathrm{CO}_{3}{ }^{2-}$ & ${\underline{H i g h ~} \mathrm{NO}_{3}^{-}}^{-}$ \\
\hline$\overline{\text { Hydroxide }}$ & 3.05 & 1.91 & 1.91 & 1.17 \\
\hline Nitrate & 1.10 & 2.14 & 2.14 & 2.84 \\
\hline Nitrite & 0.74 & 0.52 & 0.52 & 0.37 \\
\hline Aluminate & 0.27 & 0.31 & 0.31 & 0.32 \\
\hline Carbonate & 0.17 & 0.16 & 0.50 & 0.16 \\
\hline Sulfate & 0.030 & 0.15 & 0.15 & 0.22 \\
\hline
\end{tabular}

\subsection{Results and Discussion}

\subsection{Uranium}

Figures 2 and 3 present graphs of the predicted uranium concentration versus hydroxide concentration for the non-equilibrium (4-day) and equilibrium (129-day) models, respectively assuming only changes in the nitrate and hydroxide concentrations resulting from addition of nitric acid to the waste stream (i.e., no dilution of other solution components). The models calculate a significantly different dependence of uranium solubility on the hydroxide concentration. For the non-equilibrium model, the uranium concentration follows an inverted U-shape, whereas the equilibrium model predicts Ushape dependence. The predicted uranium solubility from the non-equilibrium model reflects the possible formation of supersaturated solutions or the presence of colloidal uranium resulting in higher uranium concentrations. As expected, an increase in 
carbonate concentration results in increased uranium solubility, particularly at lower hydroxide concentrations (see Figure 3).

Figure 2. Predicted Uranium Concentration versus Hydroxide Concentration using Non-equilibrium Model

Uranium Solubility - Non-equilibrium Model (4-day)

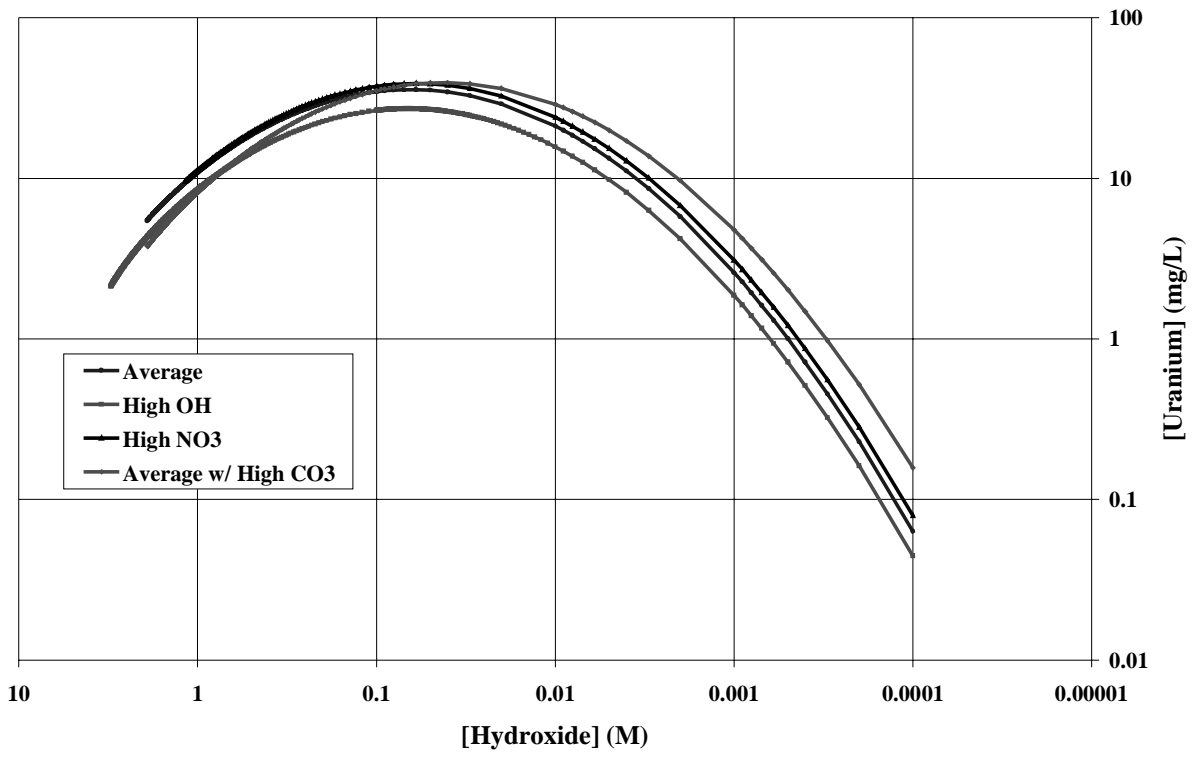

Figure 3. Predicted Uranium Concentration versus Hydroxide Concentration using Equilibrium Model

Uranium Solubility - Equilibrium Model (129-Day)

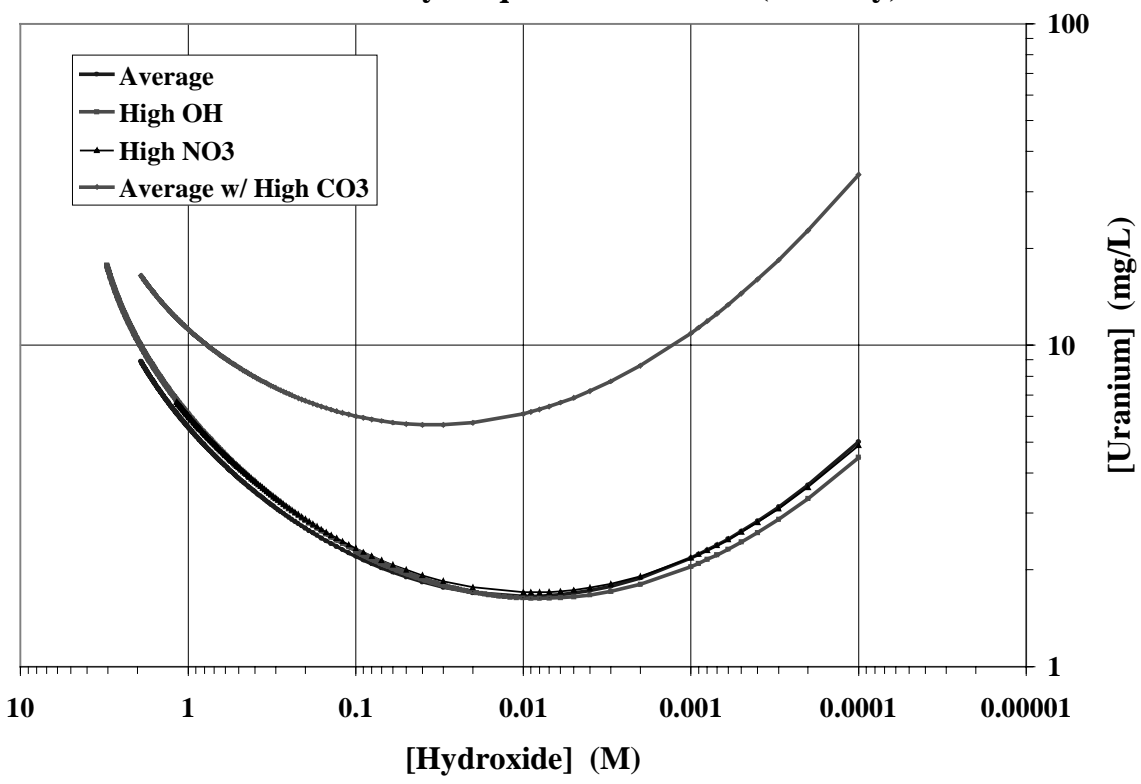




\subsection{Non-equilibrium Uranium Model}

The first case uses the non-equilibrium uranium solubility model with a waste solution composition of that represented by the "High Hydroxide" case. Figure 4 presents a graph of the predicted uranium solubility versus hydroxide concentration for the "High Hydroxide Case". With the non-equilibrium model, the predicted uranium solubility increases with decreasing hydroxide concentration until a value of about $49 \mathrm{mg} / \mathrm{L}$ uranium at a hydroxide concentration of $0.041 \mathrm{M}$. The uranium concentration then decreases with continued decrease in the hydroxide concentration.

As the waste solution enters into the CSSX stage at the predicted solubility concentration $(2.13 \mathrm{mg} / \mathrm{L})$, the solution will become diluted in uranium due to the addition of the scrub acid. Figure 3 also provides a graph of the $100 \%$ saturated uranium concentration versus hydroxide concentration resulting from dilution with scrub acid. At no time does the diluted uranium concentration exceed the predicted uranium solubility. Consequently, uranium precipitation would not occur upon contact of the waste solution with scrub acid solution.

\section{Figure 4. Predicted Uranium Concentration versus Hydroxide Concentration using the Non-equilibrium Model - High Hydroxide Case}

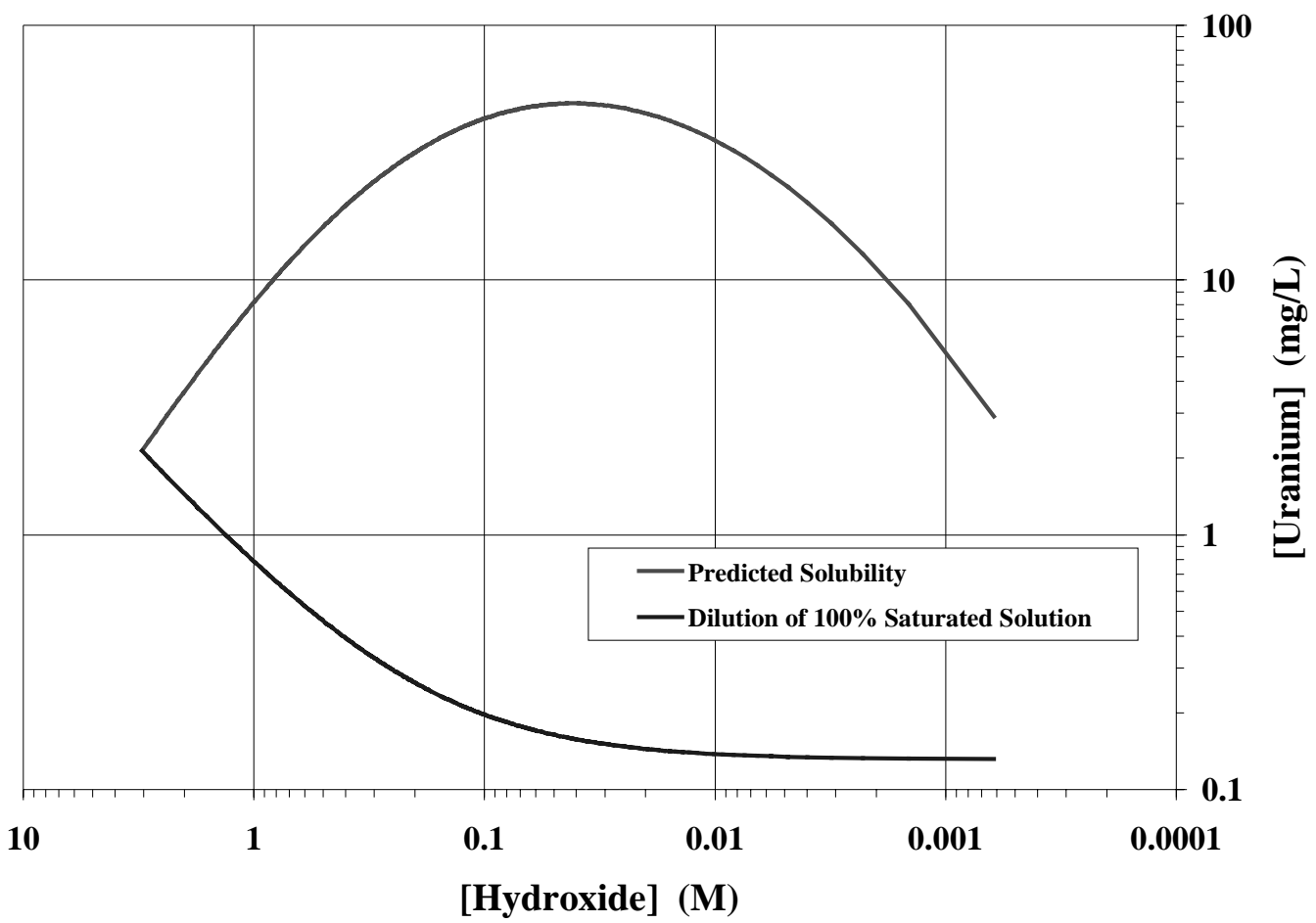

\subsection{Equilibrium Uranium Model}

Calculations also used the equilibrium model for predicting uranium solubilities with the four waste solution compositions - "High Hydroxide", "Average", "High Nitrate" and "Average with High Carbonate". Figures 5-8 present the respective graphs for predicted uranium solubilities versus hydroxide concentration as well as the uranium 
concentration upon dilution with scrub acid solution. Under normal operations scrub acid and waste solution mixes at a volume ratio of 1 part scrub acid to 15 parts of waste solution. Small variations in this ratio may exist, but would not be expected to exceed 2 parts of scrub acid to 15 parts of waste solution. Calculations indicate no precipitation occurs upon mixing scrub acid and waste solutions at both 1:15 and 2:15 ratios regardless of the degree of uranium saturation in the incoming feed solution. This is apparent in Figures 5-8 where the predicted solubility curve does not intersect any of the lines representing the degree of uranium saturation at the first two points on each graph.

In contrast to the results with the non-equilibrium model, the results indicate that precipitation of small quantities of uranium would occur under off-normal conditions when large additions of the scrub acid to the waste volume occur. We calculate the minimum dilution factors required for precipitating uranium at 9.60, 6.73, 4.47 and 6.60 for the "High Hydroxide", "Average", "High Nitrate" and "Average with High Carbonate" cases, respectively. These dilution factors assume that the waste solution entering the facility is at the solubility limit (i.e., at $100 \%$ of saturation). Maximum precipitation occurs upon higher dilution. Dilution factors producing maximum quantity of precipitated uranium solids are 16.2, 10.5, 6.84 and 10.5 for the "High Hydroxide", "Average", "High Nitrate" and "Average with High Carbonate" cases, respectively.

The large dilutions cannot occur in the CSSX contactors, but could possibly occur in the storage tank for feed of the decontaminated salt solution to the Saltstone facility. For the pilot facility, the conceptual design sets the operating volume at 1400 gallons. ${ }^{14}$ Assuming a $20 \%$ increase in the operating volume as the maximum fill volume in the storage tank, we estimate the maximum volume of diluted waste solution at 1680 gallons.

Tables III - VI present the maximum precipitated quantity of uranium for each of the four waste solution cases. The "High Hydroxide" case results in the largest uranium precipitation with a maximum quantity of 5.0 grams deposited from 1680 gallons of partially neutralized waste solution. The "Average", "High Nitrate" and "Average with High Carbonate" cases result in lower, but similar quantities of uranium precipitation (3.1, 3.1 and 4.2 grams, respectively) for the same quantity of partially neutralized waste solution. These quantities of uranium, even if the ${ }^{235} \mathrm{U}$ enrichment is $100 \mathrm{wt} \%$, are well below the fissionable mass limit of 700 grams for ${ }^{235} \mathrm{U}$. ${ }^{15}$ Since the ${ }^{235} \mathrm{U}$ enrichment in HLW is below $100 \mathrm{wt} \%$, the fractions of a critical mass represented by these predictions are conservative.

The maximum uranium precipitation occurs where the waste solution enters into the CSSX process completely saturated (i.e., 100\% saturated) in uranium. In normal operations the waste solution will first pass through the strontium/alpha stage in which addition of monosodium titanate (MST) sorbs much of the soluble actinides. This process will reduce the concentration of uranium below the solubility limit in the feed to the CSSX stage. Testing indicates that about $30 \%$ of the uranium removes upon contact of the waste with $0.4 \mathrm{~g} / \mathrm{L}$ MST. Thus, the strontium/alpha treatment will reduce the uranium content to less than $75 \%$ of the saturated value. This provides additional assurance that the quantity of precipitated uranium is small. 
A preconceptual design of a full-scale Salt Waste Processing Facility (SWPF) designates a 100,000-gallon storage tank for the decontaminated waste. ${ }^{16}$ In an off-normal event in which this tank were filled with waste and scrub acid solution leading to the maximum quantity of precipitated uranium, calculations indicate a maximum uranium precipitation of between 184 ("Average" case) and 296 ("High Hydroxide" case) grams for the four cases evaluated. The quantity of diluted waste solution requires large quantities of scrub acid solution (between 87,200 and 94,200 gallons to fill the 100,000-gallon tank). The quantity of scrub acid solution available to the CSSX operations is limited to the volume of the scrub acid feed tank (2500 gallons) in the current design for the SWPF. ${ }^{16}$ A larger quantity of scrub acid solution is present in the cold feeds Scrub Acid Makeup Tank (15000 gallons), however, there does not exist a direct line between the Scrub Acid Makeup Tank and the Decontaminated Waste Storage Tank. Thus, there is insufficient scrub acid solution to mix with waste solution to precipitate uranium in quantities that represent a criticality safety concern in the Decontaminated Waste Storage Tank.

\section{Figure 5. Uranium Concentration versus Hydroxide Concentration - "High Hydroxide" Case}

Equilibrium Uranium Model - High Hydroxide Case @ $35^{\circ} \mathrm{C}$

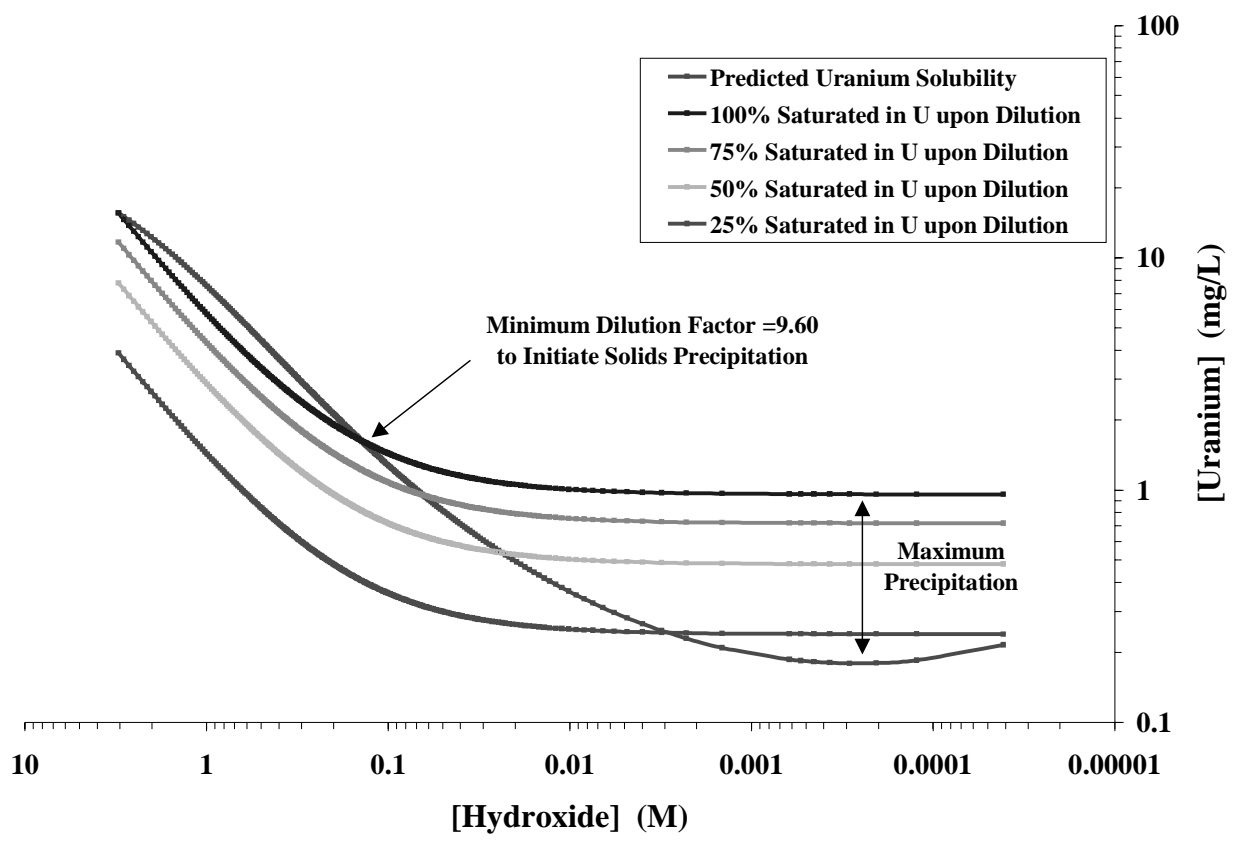


Figure 6. Uranium Concentration versus Hydroxide Concentration "Average Case"

Equilibrium Uranium Model - Average Case @ $45{ }^{\circ} \mathrm{C}$

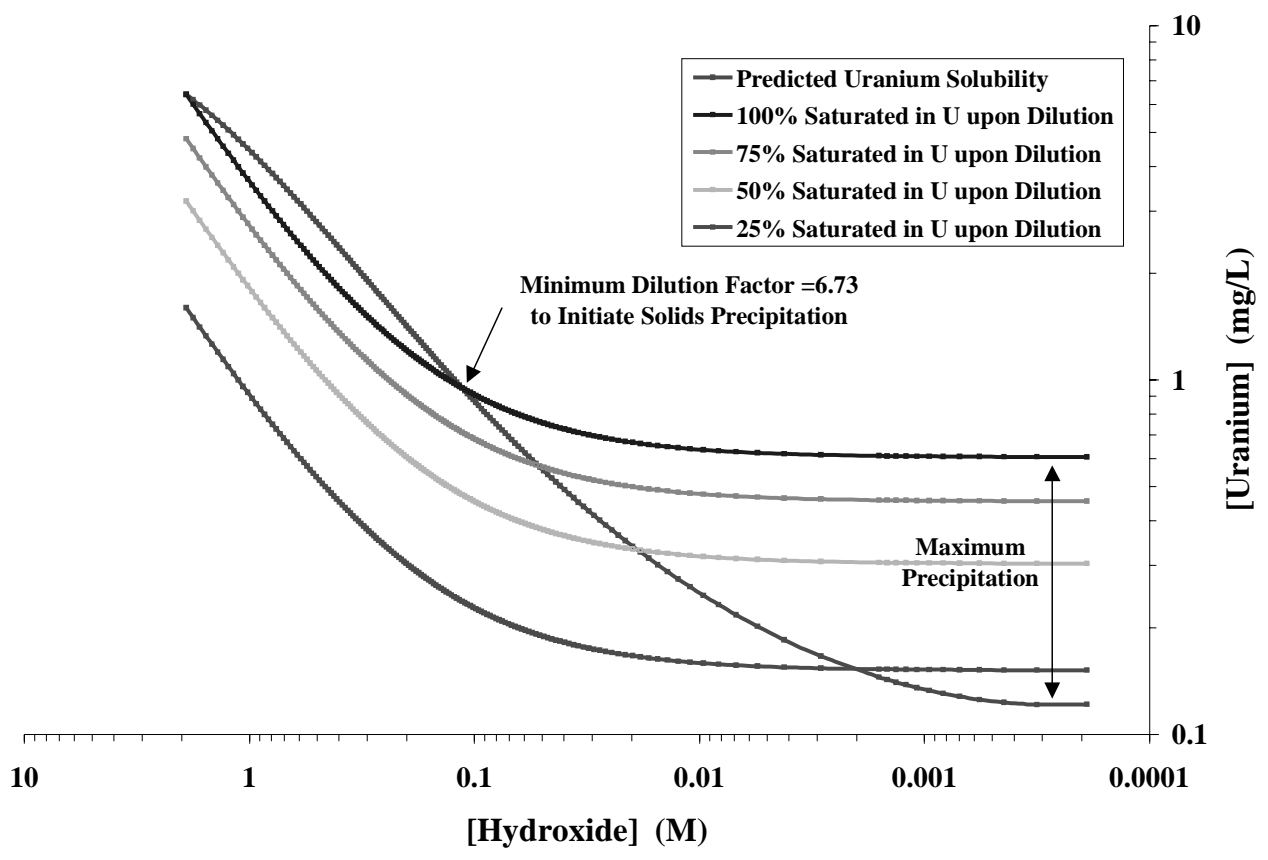

Figure 7. Uranium Concentration versus Hydroxide Concentration "High Nitrate" Case

Equilibrium Uranium Model - High Nitrate Case @ $45^{\circ} \mathrm{C}$

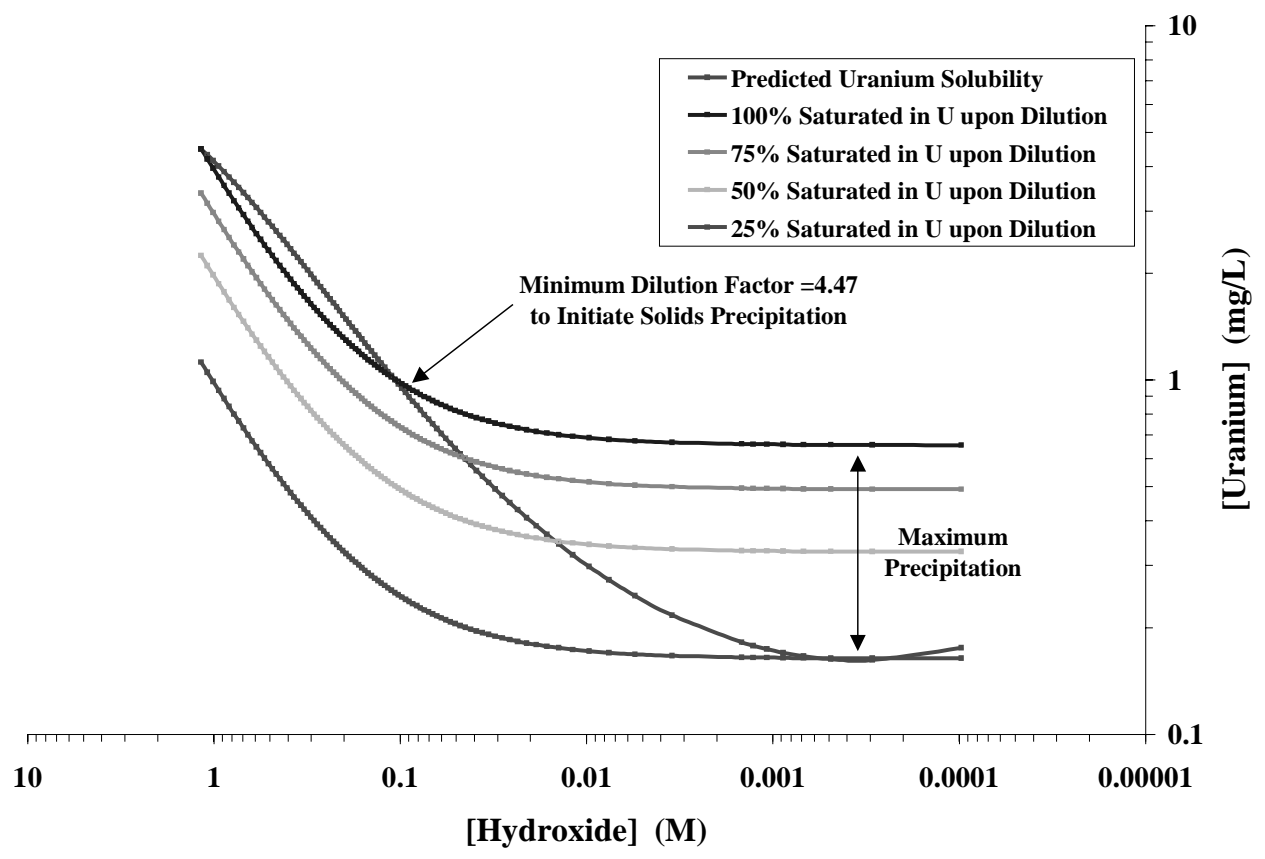


Figure 8. Uranium Concentration versus Hydroxide Concentration "Average with High Carbonate" Case

Equilibrium Uranium Model -

Average with High Carbonate Case $@ 65^{\circ} \mathrm{C}$

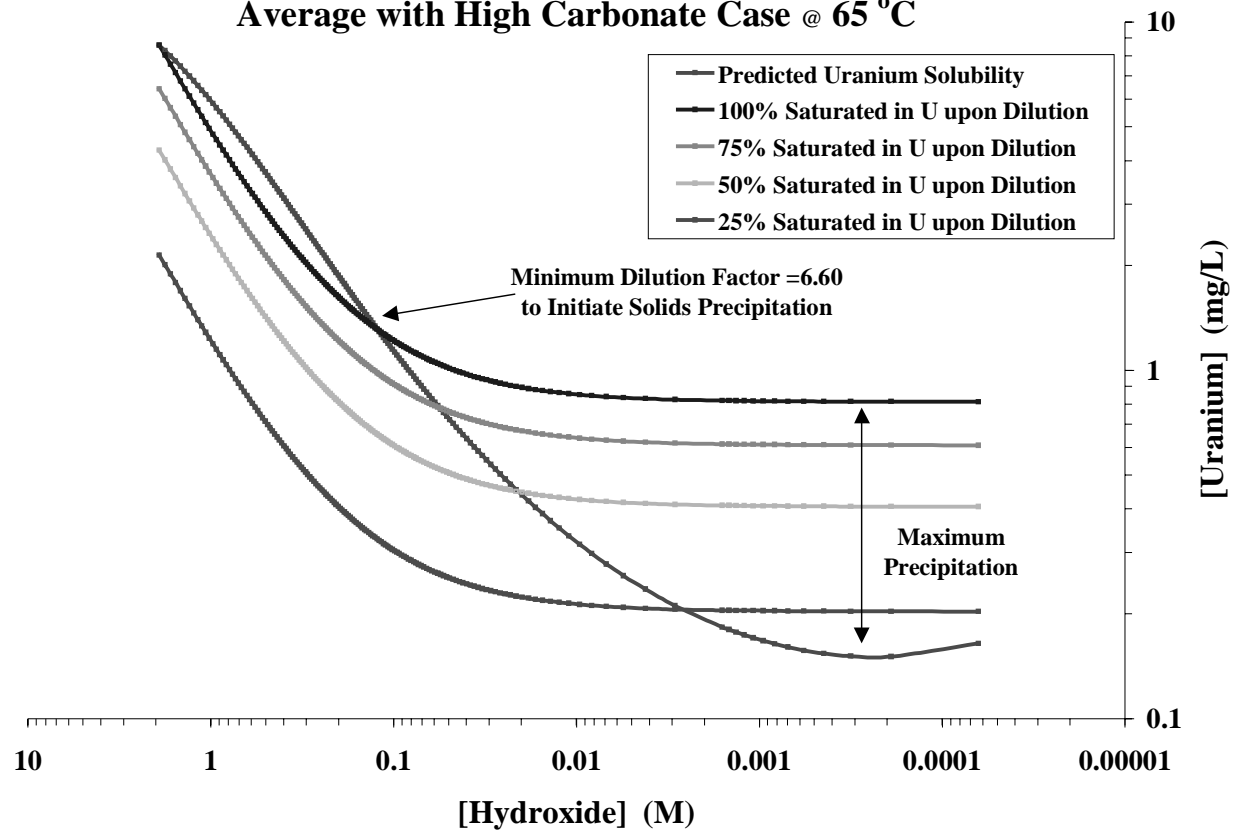

Table III. Maximum Quantities of Uranium Precipitated upon Addition of Scrub Acid Solution to "High Hydroxide" Waste Solution

\begin{tabular}{cccc} 
Case & \multicolumn{3}{c}{ Quantity of Precipitated Uranium $(\mathbf{g})$} \\
100\% saturated & $\frac{\mathbf{1 0 0 0 ~ L}}{0.78}$ & $\frac{\mathbf{1 6 8 0} \text { gal }}{5.0}$ & $\frac{\mathbf{1 0 0 , 0 0 0} \text { gal }}{296}$ \\
75\% saturated & 0.54 & 3.4 & 205 \\
50\% saturated & 0.30 & 1.9 & 114 \\
25\% saturated & 0.061 & 0.39 & 23
\end{tabular}

Table IV. Maximum Quantities of Uranium Precipitated upon Addition of Scrub Acid Solution to "Average" Waste Solution

\section{Case}

$100 \%$ saturated

$75 \%$ saturated

$50 \%$ saturated

$25 \%$ saturated
Quantity of Precipitated Uranium (g)

$\underline{1000 \mathrm{~L}} \quad \underline{1680 \text { gal }} \quad \underline{100,000 \text { gal }}$

$\frac{1000}{3.1} \quad \frac{1680}{184}$

0.33

2.1

126

0.18

1.2

69

0.030

0.19

11 
WSRC-TR-2002-00054

Table V. Maximum Quantities of Uranium Precipitated upon Addition of Scrub Acid Solution to "High Nitrate" Waste Solution

\begin{tabular}{cccc} 
Case & \multicolumn{3}{c}{ Quantity of Precipitated Uranium $(\mathbf{g})$} \\
$100 \%$ saturated & $\frac{\mathbf{1 0 0 0} \mathbf{L}}{0.49}$ & $\frac{\mathbf{1 6 8 0} \text { gal }}{3.1}$ & $\frac{\mathbf{1 0 0 , 0 0 0} \text { gal }}{187}$ \\
$75 \%$ saturated & 0.33 & 2.1 & 125 \\
$50 \%$ saturated & 0.17 & 1.1 & 63 \\
25\% saturated & 0.0019 & 0.012 & 0.72
\end{tabular}

Table VI. Maximum Quantities of Uranium Precipitated upon Addition of Scrub Acid Solution to "Average with High Carbonate" Waste Solution

\begin{tabular}{cccc} 
Case & \multicolumn{3}{c}{ Quantity of Precipitated Uranium $(\mathbf{g})$} \\
$100 \%$ saturated & $\frac{\mathbf{1 0 0 0} \text { L }}{\mathbf{1 6 8 0} \text { gal }}$ & $\frac{\mathbf{1 0 0 , 0 0 0 \text { gal }}}{251}$ \\
$75 \%$ saturated & 0.66 & 4.2 & 174 \\
$50 \%$ saturated & 0.26 & 2.9 & 97 \\
$25 \%$ saturated & 0.052 & 0.33 & 20
\end{tabular}

\subsection{Plutonium}

The prediction equation for plutonium concentration contains only hydroxide concentration terms. As with uranium, our calculations featured the "High Hydroxide", "Average" and "High Nitrate" solution compositions. The "Average with High Carbonate" case was not evaluated since the predicted plutonium solubility is the same value as that for the "Average" case (i.e., prediction equation does not include a term for carbonate concentration).

Figure 9 provides a graph of the predicted plutonium concentration versus the hydroxide concentrations upon addition of nitric acid to the "High Hydroxide" waste solution. . Similar graphs (not shown) are obtained with the "Average" and "High Nitrate" compositions. The red line represents the predicted solubility as a function of hydroxide concentration. Unlike uranium, the addition of scrub acid at either 1 part or 2 parts of scrub acid to 15 parts of waste solution results in the plutonium concentration of the slightly neutralized and diluted waste solution exceeding the predicted solubility. As a consequence, precipitation of small quantities of plutonium could occur. 
Figure 9. Predicted Plutonium Concentrations upon Addition of Nitric Acid

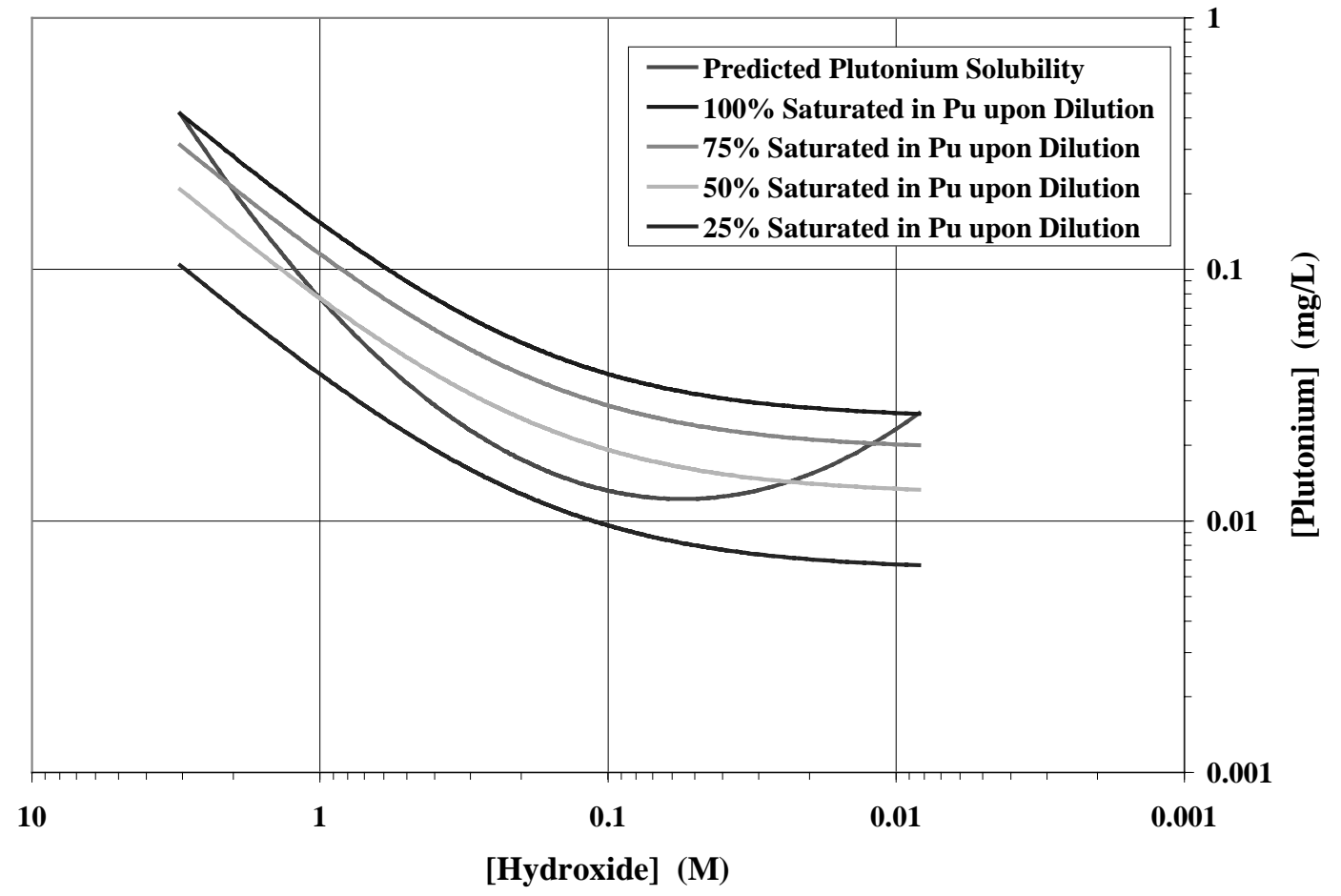

Maximum accumulation of precipitated plutonium will occur in the Decontaminated Waste Storage Tank. With a maximum fill capacity of 1680 gallon in the pilot-scale facility, less than 0.25 grams of plutonium would precipitate in this tank for the "High Hydroxide" composition (see Table VII). For the full-scale facility with a maximum fill capacity of 100,000 gallons, we estimate the maximum quantity of precipitated plutonium at 14 grams. We predict plutonium precipitation to occur with the "Average" and "High Nitrate" compositions as well. However, the quantities of precipitated plutonium fall below those predicted for the "High Hydroxide" composition (see Table VII).

We developed the plutonium solubility prediction equation from a number of data sets that had a variable makeup of anionic components. Temperature was not a controlled parameter in all of the data sets. Consequently, the prediction model features only hydroxide terms and includes a rather broad $95 \%$ confidence interval. The large confidence interval adds approximately a factor of 4.6 to the maximum plutonium solubility. Thus, applying a factor of 4.6 to the predicted quantities of precipitated plutonium conservatively bounds the quantity of precipitated plutonium. Even with the factor of 4.6 applied to the values presented in Table VII, the predicted quantities of precipitated plutonium in all of the compositional cases is less than or equal to 1.1 and 64 grams for the pilot-scale and full-scale facilities, respectively. These quantities are well below the fissionable mass limit of 450 grams for ${ }^{239} \mathrm{Pu} .{ }^{15}$ 
WSRC-TR-2002-00054

Table VII. Quantities of Precipitated Plutonium Accumulated During Normal Operations.

\section{Composition}

High Hydroxide

Average

High Nitrate

Composition

High Hydroxide

Average

High Nitrate

\author{
Quantity of Precipitated Plutonium (grams) \\ in Pilot-Scale Facility (1680 gallons) \\ $\underline{@ 15: 1^{*}} \quad \underline{@ 15: 2^{*}}$
}

0.14

0.24

0.051

0.090

0.0020

0.0032

Quantity of Precipitated Plutonium (grams)

in Full-Scale Facility (100,000 gallons)

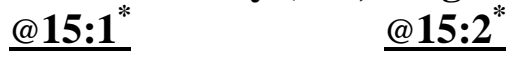

8.0

14

3.0

5.3

1.2

2.1

${ }^{*}$ volume ratio of waste solution to scrub acid solution

We also evaluated plutonium solubilities in the event of off-normal operations in which large quantities came into contact with the waste solution saturated in plutonium between 25 and $100 \%$. Calculations indicate a minimum plutonium solubility of $0.012 \mathrm{mg} / \mathrm{L}$ occurs at a hydroxide concentration of about 0.055 molar for the "High Hydroxide" composition. The other cases represent the predicted plutonium concentrations upon dilution of a solution initially saturated, $75 \%$ of saturation, $50 \%$ of saturation and $25 \%$ of saturation in plutonium.

The calculations suggest precipitation of plutonium when the diluted concentrations fall above the predicted solubility. Inspection of Figure 7 reveals that precipitation of plutonium does not occur if the initial solution remains at $25 \%$, or less, of the solubility or saturated in plutonium. A solution completely saturated in plutonium will precipitate plutonium upon addition of the scrub acid and reduction in the hydroxide concentration. Plutonium will also precipitate from solutions initially at $75 \%$ and $50 \%$ of the plutonium solubility value. Precipitation occurs in these cases after adding sufficient scrub acid to lower the hydroxide concentration from $3.0 \mathrm{M}$ to $2.0 \mathrm{M}$ and $1.0 \mathrm{M}$, respectively.

Maximum plutonium precipitation occurs when the greatest difference exists between the predicted solubility and the diluted plutonium concentration. Table VIII provides the maximum concentration difference and total quantity of precipitated plutonium solids for each calculated case. The calculated total quantity of solids assumes three different diluted waste volumes resulting from contacting with scrub acid: (1) 1000 liters, (2) 1680 gallons and (3) 100,000 gallons. 
WSRC-TR-2002-00054

\section{Table VIII. Concentration and Quantity of Precipitated Plutonium Solids During Off-Normal Operations}

\begin{tabular}{|c|c|c|c|c|}
\hline \multirow[b]{2}{*}{ Case } & \multirow{2}{*}{$\begin{array}{c}\text { Maximum } \\
\text { Difference } \\
{[\mathbf{P u}](\mathrm{mg} / \mathrm{L})}\end{array}$} & \multicolumn{3}{|c|}{ Quantity of Precipitated Plutonium (g)* } \\
\hline & & $1000 \mathrm{~L}$ & $1680 \mathrm{gal}$ & 100,000 gal \\
\hline $100 \%$ saturated & 0.084 & 0.084 & 0.53 & 32 \\
\hline $75 \%$ saturated & 0.038 & 0.038 & 0.24 & 14 \\
\hline $50 \%$ saturated & 0.0096 & 0.0096 & 0.061 & 3.6 \\
\hline $25 \%$ saturated & 0 & 0 & 0 & 0 \\
\hline
\end{tabular}

From the calculations, the quantity of precipitated plutonium remains less than 0.60 grams in the Storage Tank in the Pilot-Scale Salt Processing Facility and less than or equal to 32 grams upon the production of 100,000 gallons of partially neutralized waste solution having the minimum plutonium solubility in the Storage Tank for Feed to Saltstone in the full-scale SWPF. Applying the same factor of 4.6 as previously described to bound the precipitated plutonium quantities results in the maximum plutonium solids accumulation of 2.4 and 150 grams for the pilot-scale and full-scale facilities, respectively.

The maximum plutonium precipitation occurs in the case where the waste solution enters into the CSSX process completely saturated (i.e., 100\% saturated) in plutonium. In normal operations, the waste solution will first pass through the strontium/alpha removal stage in which addition of monosodium titanate sorbs much of the soluble actinides. This process will reduce the incoming concentration of plutonium well below the solubility limit. Based on an average blend of saltcake and supernates, the decontamination factor for plutonium is targeted at 12. MST performance testing has demonstrated an average DF of about 12 with simulated waste solutions containing 0.1 to $0.2 \mathrm{mg} / \mathrm{L}$ of plutonium. ${ }^{17}$ Thus, the strontium/alpha treatment will reduce the plutonium content of an initially saturated waste to less than $10 \%$ of the completely saturated value. As apparent from Figure 9 and Table VIII, if the waste solution entering the CSSX stage remains at or below $25 \%$ of the solubility value, the model predicts that no plutonium will precipitate upon contact with scrub acid.

For selected wastes with a high dissolved uranium content and an elevated plutonium activity, the process will not achieve the targeted decontamination. ${ }^{18}$ The elevated plutonium content arises primarily from wastes containing non-fissile ${ }^{238} \mathrm{Pu}$. This plutonium isotope exhibits a much higher specific activity than the fissile isotopes of plutonium. The current waste acceptance criteria for Saltstone are based on an activity per unit mass of waste solution. Thus, those wastes with elevated plutonium activities do not pose a greater nuclear criticality risk since the mass concentration of fissionable plutonium isotopes is not significantly greater than that evaluated in the preceding discussion. 


\subsection{Equivalent ${ }^{235} \mathrm{U}$}

We also calculated an equivalent ${ }^{235} \mathrm{U}$ quantity by summing the quantities of precipitated uranium and four times the precipitated plutonium. This would provide a bounding total fissile quantity precipitated upon partial neutralization of the waste with the scrub acid solution. Figure 10 provides a graph of the calculated equivalent ${ }^{235} \mathrm{U}$ quantity as a function of hydroxide concentration for the "High Hydroxide" case that could accumulate in the Decontaminated Salt Solution Storage Tank (1680 gallons). Previously we reported that this case provided the highest individual quantities of precipitated uranium and plutonium.

The graph exhibits three distinct regions. Initially, at high hydroxide concentration, only plutonium precipitates and contributes to the equivalent ${ }^{235} \mathrm{U}$ quantity. At a hydroxide concentration of $0.139 \mathrm{M}$, uranium precipitation initiates. From this point, both plutonium and uranium precipitate and contribute to the equivalent ${ }^{235} \mathrm{U}$ quantity. At a hydroxide concentration of $0.008 \mathrm{M}$, plutonium precipitation ceases. Below this concentration only uranium precipitates.

Note that maximum quantity of equivalent ${ }^{235} \mathrm{U}$ occurs in the region when only uranium precipitates. Thus, the simultaneous precipitation of uranium and plutonium does not result in larger quantities of equivalent ${ }^{235} \mathrm{U}$. Therefore, the bounding quantity of fissile material is that produced solely by the precipitation of uranium at low hydroxide concentrations and previously reported in Tables III - VI.

Figure 10. Quantity of Equivalent ${ }^{235} \mathrm{U}$ Precipitated in the Pilot-Scale Decontaminated Salt Solution Storage Tank (1680 gallons)

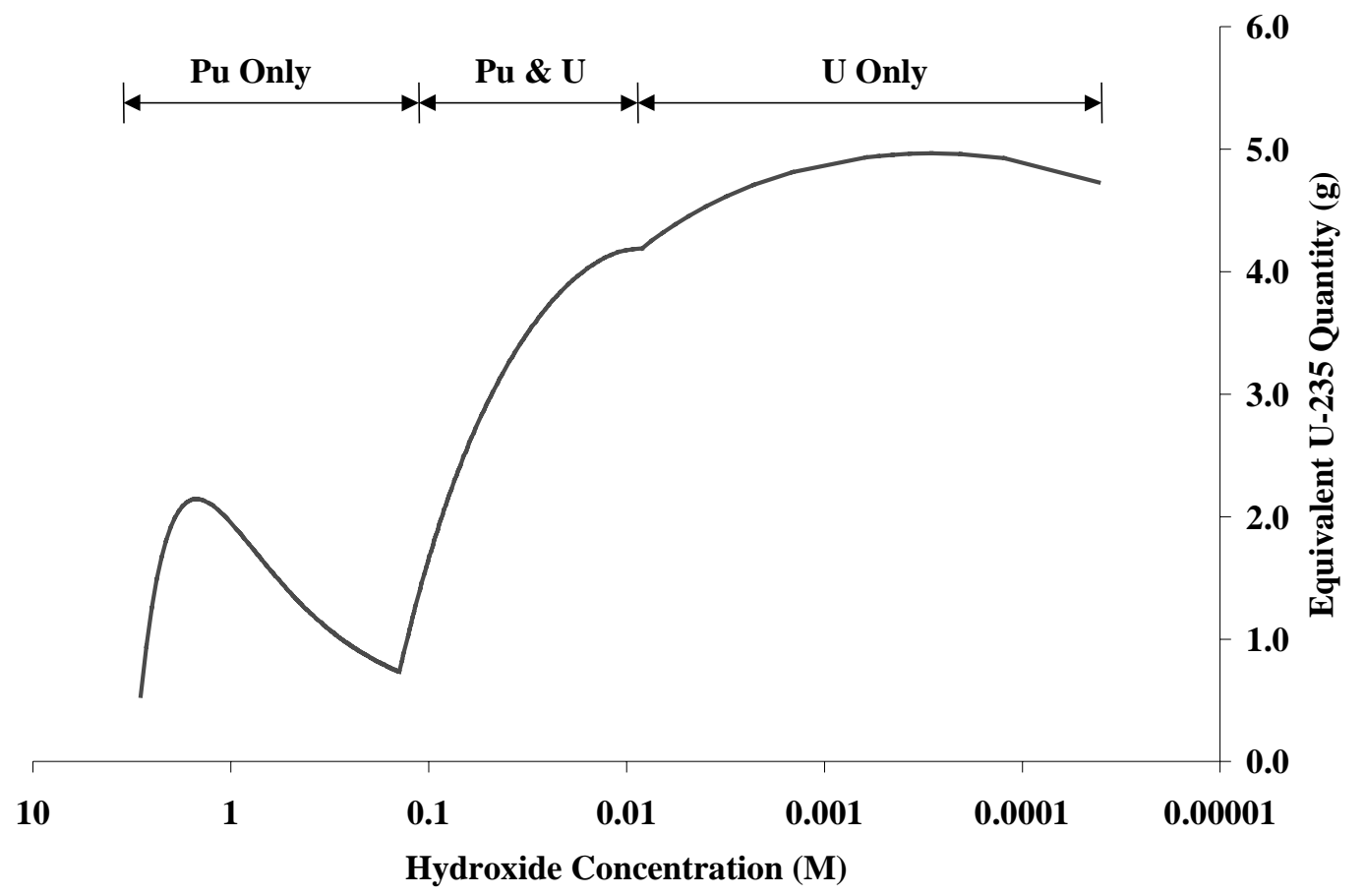


WSRC-TR-2002-00054

\subsection{Summary and Conclusions}

Models predict that uranium and plutonium concentrations can exceed the predicted solubilities when scrub acid solution ( $0.2 \mathrm{M}$ nitric acid) mixes with alkaline waste solutions in the caustic-side solvent extraction (CSSX) stages of the planned Salt Processing Pilot Plant Facility and the full-scale Salt Waste Processing Facility. However, in all cases, including the simultaneous precipitation of uranium and plutonium, the quantities of precipitated uranium and plutonium solids are well below the fissionable mass limits for ${ }^{235} \mathrm{U}$ and ${ }^{239} \mathrm{Pu}$.

Under normal operations at nominal contact volumes and times, the prediction models indicate that uranium would not precipitate in the CSSX stage, but could precipitate after mixing with large volumes of scrub acid solution and extended storage in the decontaminated waste solution storage tanks. We estimate that the maximum quantity of uranium precipitated in the pilot plant facility (diluted waste volume of 1680 gallons) at 5.0 grams and in the full-scale facility at 296 grams (dilute waste volume of 100,000 gallons). These quantities are well below the ${ }^{235} \mathrm{U}$ mass limit of 700 grams.

Under normal operations at nominal contact volumes, plutonium precipitation could occur during the CSSX stage if the waste solution enters saturated in plutonium. However, we estimate that the maximum quantity of plutonium precipitated in the pilot plant facility at 1.1 grams and in the full-scale facility at 150 grams at the fully saturated conditions. These quantities are well below the fissionable mass limit for ${ }^{239} \mathrm{Pu}$ of 450 grams. In actuality, the quantities of plutonium will be much lower than this value as greater than $90 \%$ of the plutonium in the feed waste solution will be removed during the Sr/Alpha separation process prior to processing in the CSSX stage.

\subsection{Quality Assurance}

All calculations reported in this document used Microsoft Excel version 97 SR-2(h) software loaded onto an IBM ThinkPad T22 Model 26478EU. File names for the calculations include "PuCalcs", "UCalcs Full 4d" and "U Calcs Full Model 129day". Printouts of all worksheets and graphs are recorded in laboratory notebook WSRC-NB2000-00233 assigned to D. T. Hobbs.

\subsection{References}

1 "Record of Decision: Savannah River Site Salt Processing Alternatives," Federal Register: Volume 66, Number 201, pages 52752-52756, October 17, 2001.

2 P. V. Bonnesen, L. H. Delmau, B. A. Moyer, and R. A. Leonard, "A Robust AlkalineSide CSEX Solvent Suitable for Removing Cesium from Savannah River High Level Waste," Solvent Extraction and Ion Exchange, 18(6), 1079 (2000). S. G. Campbell, M. W. Geeting, C. W. Kennell, J. D. Law, R. A. Leonard, M. A. Norato, R. A. Pierce, T. A. Todd, D. D. Walker, and W. R. Wilmarth, "Demonstration of Caustic-Side Solvent Extraction with Savannah River Site High Level Waste," WSRC-TR-2001-00223, Rev. 0, April 19, 2000.

4 G-FDD-J-00002, Rev. B, Caustic Side Solvent Extraction Pilot Facility Description.

5 R. H. Ross, "Preliminary Nuclear Criticality Safety Evaluation: CSSX Salt Processing 
WSRC-TR-2002-00054

Pilot Facility (U)," N-NCS-H-00125, Rev. 0, July 23, 2001.

6 P. D. d'Entremont and D. T. Hobbs, "Migration of Uranium from Tank 43H Sludge," WSRC-TR-2001-00127, Rev. 0, March 29, 2001.

7 W. R. Wilmarth and D. T. Hobbs, "Task Technical and Quality Assurance Plan Supporting CSSX Pilot Plant Criticality Issues," WSRC-RP-2001-00786, Rev. 0, August 17, 2001.

8 S. Campbell, "Uranium/Plutonium Precipitation when Scrub Acid Contacts Waste Solution," HLW-SDT-TTR-2001-00001, Rev. 0, July 16, 2001.

9 D. T. Hobbs and T. B. Edwards, "Solubility of Uranium in Alkaline Salt Solutions (U)," WSRC-TR-93-454, March 29, 1994.

${ }^{10}$ D. T. Hobbs and T. B. Edwards, "Solubility of Plutonium in Alkaline Salt Solutions (U)," WSRC-TR-93-131, February 26, 1993.

${ }^{11}$ R. A. Leonard, D. B. Chamberlain and C. Conner, "Centrifugal Contactors for Laboratory-Scale Solvent Extraction Tests," Sep. Sci. Technol. 32(1-4), 193-210 (1997).

${ }^{12}$ R. A. Leonard, Scott B. Aase, Hassan A. Arafat, David B. Chamberlain, Cliff Conner, Monica C. Gegalbuto and George F. Vandergrift, "Interim Report on a Multi-Day Test of the Caustic-Side Solvent Extraction Flowsheet for Cesium Removal from a Simulated SRS Tank Waste," ANL-01/10, April 2001.

${ }^{13}$ D. D. Walker, "Preparation of Simulated Waste Solutions," WSRC-TR-99-00116, Rev. 0, April 15, 1999.

${ }^{14}$ Salt Processing Pilot Plant Caustic Side Solvent Extraction Pilot Facility Process Flow Diagram, Sheet 2, MM7S0002, Rev. C.

15 ANSI/ANS-8.1-1998, Nuclear Criticality Safety in Operations with Fissionable Materials Outside of Reactors.

${ }^{16}$ High-Level Waste Salt Processing Caustic Side Solvent Extraction Process Flow Diagram, XM5H0053, Rev. G.

${ }^{17}$ D. T. Hobbs, M. S. Blume, H. L. Thacker, "Phase V Testing of Monosodium Titanate Adsorption Kinetics," WSRC-TR-2000-00142, May 24, 2000.

${ }_{18}$ M. J. Barnes, D. T. Hobbs, M. C. Duff and S. D. Fink, "Permanganate Reduction of Savannah River Site Actual Waste Samples for Strontium and Actinides Removal," WSRC-TR-2002-00048, Rev. 0, February 21, 2002. 